our ration. Such a diet is furnished by rolled oats (40), gelatin (10), casein (5), dextrin (40.3), butterfat (1), and salts (3.7) (McCollum). It is perhaps also pertinent to point out that we have dettected an invariable sign of inadequacy in the A factor of greater delicacy than those hitherto employed and may thus recognize such inadequacy long before growith impairment, for instance. The sign is consitituted by a highly characteristic aberration of the cstrous cycle. And we have been able to demonstrate the persistence of fertility with a wheat-milk ration. (Sherman) even in the aksence of butterfat and when the A deficiency is heralded by the continuous exhibition of the new sign. The beneficial effect of a very high percentage of butterfait, consequently, seems preferably explained by its possession of a definite though low quota of the fertility conferring substance. Furthermore, a sample of cod liver oil tested by us and proven to possess a much superior A content to butterfat is far less efficacious than butter in curing or preventing the impairment of the reproductive function.

The beneficial dietary factor can not be identical with the antiscorbutic vitamine $\mathrm{C}$, for curative effects have been secured when ground whole wheat was added ito our purified ration, and the cereals are, of course, noitaibly deficient in C. Moreover, lalthough some ofavorable influence on growth has lbeen noted, it has been impossible for us to secure with orange juice the fertility effects so evident with lelttuce.

Lastly, we may refer to the suggestions either implied or expressed in the publications of some investigators (Osborne and Mendel, Kennedy and Palmer) that yeast contains some toxic substance inimical to the organs of generation and hence eausing sterility or that it simply does not contain enough of the water soluble vitamine B. The curative foods could hardly be assumed to detoxify. Nor do we believe our animals suffered from lack of $B$, for growth was excellent; iand as much as 25 per cent. by weight of yeast (which must have given a great surplus of $\mathrm{B}$ ) did not change the result. Fertility, when wheat germ is used as a source for B, results not from more B but because wheat germ is also rich in $X$.
We have undertaken a series of experiments. designed to trace further in natural foods the distribution of the substance thus shown to be indispensable for the production of healthy young.

Herbert M. Evans

K. SCOTT BISHOP

\section{THE RECENT SCIENTIFIC WORK OF ROBERT WHEELER WILLSON}

IT must be of interest to the many friends and former students of Professor Robert W. Willson to know that the last months of his. life were actively occupied in the successful solution of centain scientific problems.

Professior Willson died ait his home in Cambridge, November 1, 1922, in the seventieth year of his age. He was a graduate of Harvard College in the class of 1873, and took his $\mathrm{Ph} . D$. at Würzburg a few years later, after specializing in physics, a subject which, in conjunction with his astronomical experience, gave just the right equipment for his solution of aerial navigation problems at a much later daite.

The main facts of his professional career are available in the biographical reference books, while others can speak more fully than I of his devotion to the building up of a department of astronomy in Harvard College. Following his retirement as professor emeritus in 1919, he devoited an increasing amount of time to his own work in Cambridge along the line of air navigation instruments, and this later work is not perhaps so well known.

His development of the air-craft sextant was. a notable achievement successfully demonstrated during the war, and widely adopted since. Anti-aircraft defense, trans-Atlantic flight, and ground speed indicators were only a few of the subjects which claimed his keenesit attenition and in which definite progress. had been marde. He was fully aware of all the trying obstacles which must be met in the development of instruments for practical airplane use, and noit only had a sound, scientific solution in readiness for each case, buit was equally alert to suggest the most economical method of construction. 
Some of this material had been prepared for publication in the form of a paper on $\Lambda$ ir Navigation and sent to press early in October, following which his attention was eagerly concentrated on further problems. So the end came like a ship holding its course accurately, and passing out of sight with all sails set.

Pittisburgh, Pa.

M. H. D.

'Novenber 6, 1922

\section{SCIENTIFIC EVENTS}

\section{MORTALITY FROM CANCER}

THE Department of Commerce announces that the returns compiled by the Bureau of the Census show that over 76,000 deaths were due to cancer in the death registration area of the United States in 1921, and assuming that the rest of the United States had as many deaths from this cause in proportion to the population, the total number of deaths from eancer in the entire United States for 1921 was 93,000, while for 1920 the number is estimated as 89,000 or 4,000 less than for 1921.

The trend of the cancer death rate is upward, the rate for 1921 being higher than that for any earlier year in twenty-three of the thintyfour states. The cancer death rate in the registration area in 1921 was 86 per 100,000 population, against 83.4 for 1920 . In comparing the death rate from cancer in one state with that in another, the bureau uses "adjusted" rates in order to make allowance for differences in the age and the sex distribution of the population, because, generally speaking, only persons in middle life and old age have eancer, so that a state with many old persons may be expected to have more deaths from cancer than a state with comparatively few old persons.

The highest "adjusted" cancer rate for 1921 is 99.6 per 100,000 population for the state of Massachusetts, and the lowest is 47.6 for the state of South Carolina. For a few states adjusted rates have been ealculated separately for the white and colored population. In this group of states the highest adjusted eancer rate for the white population is 95.9 per
100,000 population for New York and the highest rate for the colored population is 90.6, also for New York. The lowest adjusted cancer rate for the white population is 51.5 for Tennessee and the lowest for the colored population is 36.4 for Florida.

The adjusted rates show that the northern states have comparatively high and the southern states comparatively low cancer mortality, while there is little difference between the adjusted cancer rates of the white and colored races of the same states.

\section{COLORS FOR TRAFFIC SIGNALS}

THIRTY-NINE men, representing as many administrative bodies, trade associations, scientific or technical societies, and government departments, make up the sectional committee on colors for traffic signals which was organzed at a-meeting in New York City on November 9 under the auspices of the Ameriean Engineering Standards Committee. In opening the meeting, P. G. Agnew, secretary of the Ameriican Engineering Standards Committee, said that this was unquestionably the most representative group that has ever come together anywhere in the world to discuss this subject.

The commintee elected as its officers the following representatives of the three sponsors for the code: Chairman, Charles J. Bennett, state highway "commissioner of Connecticut, representing the American Association of State Highway Officials; vice-chairman, Dr. M. G. Lloyd, representing the United States Bureau of Standards; secretary, Walter S. Paine, research engineer, AEtna Insurance Company, Hartford, Conn., representing the National Safety Council.

Because of the difficulty of bringing the entire sectional committee together at frequent intervals an executive committee was appointed with instructions to collect information on the subjects coming within the seope of the code, to digest this information, to appoint subcommittees, to arrange for the necessary research work, and to draft definite recommendations for the consideration of the sectional committee. The executive committee consists of the following: 